\title{
Bioinformatic and phylogenetic analysis of the CLAVATA3/EMBRYO-SURROUNDING REGION (CLE) and the CLE-LIKE signal peptide genes in the Pinophyta
}

Timothy J Strabala*, Lorelle Phillips, Mark West and Lisa Stanbra

\begin{abstract}
Background: There is a rapidly growing awareness that plant peptide signalling molecules are numerous and varied and they are known to play fundamental roles in angiosperm plant growth and development. Two closely related peptide signalling molecule families are the CLAVATA3-EMBRYO-SURROUNDING REGION (CLE) and CLE-LIKE (CLEL) genes, which encode precursors of secreted peptide ligands that have roles in meristem maintenance and root gravitropism. Progress in peptide signalling molecule research in gymnosperms has lagged behind that of angiosperms. We therefore sought to identify CLE and CLEL genes in gymnosperms and conduct a comparative analysis of these gene families with angiosperms.
\end{abstract}

Results: We undertook a meta-analysis of the GenBank/EMBL/DDBJ gymnosperm EST database and the Picea abies and P. glauca genomes and identified 93 putative CLE genes and 11 CLEL genes among eight Pinophyta species, in the genera Cryptomeria, Pinus and Picea. The predicted conifer CLE and CLEL protein sequences had close phylogenetic relationships with their homologues in Arabidopsis. Notably, perfect conservation of the active CLE dodecapeptide in presumed orthologues of the Arabidopsis CLE41/44-TRACHEARY ELEMENT DIFFERENTIATION (TDIF) protein, an inhibitor of tracheary element (xylem) differentiation, was seen in all eight conifer species. We cloned the Pinus radiata CLE41/44-TDIF orthologues. These genes were preferentially expressed in phloem in planta as expected, but unexpectedly, also in differentiating tracheary element (TE) cultures. Surprisingly, transcript abundances of these TE differentiation-inhibitors sharply increased during early TE differentiation, suggesting that some cells differentiate into phloem cells in addition to TEs in these cultures. Applied CLE13 and CLE41/44 peptides inhibited root elongation in Pinus radiata seedlings. We show evidence that two CLEL genes are alternatively spliced via 3'-terminal acceptor exons encoding separate CLEL peptides.

Conclusions: The CLE and CLEL genes are found in conifers and they exhibit at least as much sequence diversity in these species as they do in other plant species. Only one CLE peptide sequence has been 100\% conserved between gymnosperms and angiosperms over 300 million years of evolutionary history, the CLE41/44-TDIF peptide and its likely conifer orthologues. The preferential expression of these vascular development-regulating genes in phloem in conifers, as they are in dicot species, suggests close parallels in the regulation of secondary growth and wood formation in gymnosperm and dicot plants. Based on our bioinformatic analysis, we predict a novel mechanism of regulation of the expression of several conifer CLEL peptides, via alternative splicing resulting in the selection of alternative C-terminal exons encoding separate CLEL peptides.

Keywords: CLE peptide ligands, CLEL peptide ligands, Pinophyta, Conifers, Phylogenetic analysis, Pine tracheary element system

\footnotetext{
*Correspondence: strabala@clear.net.nz

Scion, 49 Sala St, PO Box 3020, Rotorua 3010, New Zealand
} 


\section{Background}

Since the identification of CLAVATA3 (CLV3) in the dicot Arabidopsis thaliana [1], homologues and/or orthologues of this gene, known as the CLV3-EMBRYO-SURROUNDING REGION (CLE) gene family [2-4], have been identified in nearly every major plant phylogenetic clade from which large-scale genomic or EST sequence data are available, including monocots (rice, wheat) and a bryophyte moss (Physcomitrella patens). The functional roles for most CLE genes are still unknown. However, the roles for all $C L E$ genes that have been established, including $C L V 3$, are in the regulation of seed development [5] or the homeostasis of meristematic tissues reviewed in [6], including the shoot apical meristem (SAM) (CLV3) [1,7], root apical meristem (RAM) (CLE40) [8], vascular cambium (CLE41/44-TRACHEARY ELEMENT DIFFERENTIATION FACTOR (CLE41/44-TDIF)) [9], and root nodule meristems in several legume species (LjCLE-RS1/2; Mt CLE12/13; GmRIC1/2) [10-12]. As such, CLE peptides play critical roles in the establishment, regulation and maintenance of plant architecture from the earliest stages of development.

Although putative CLE genes have been identified in monocot species that appear to encode multiple CLE peptides that are presumably post-translationally processed [3], most plant CLE genes are readily identified by several common structural motifs (Figure 1). Generally, the precursor protein coding sequence is approximately 240-300 nt (80-100 aa) in length. Within these sequences are found signal peptide motifs ranging in length from 45-90 nt (15-30 aa), followed by highly degenerate non-conserved sequences (NCS1) ranging from 120-240 nt (40-80 aa) followed by the CLE motif [2-4], a $42 \mathrm{nt}(14 \mathrm{aa})$ segment that contains the mature CLE peptide sequence, which is reported to be a 12-13 aa hydroxyprolinated, triarabinosylated peptide in Arabidopsis [13-15]. In most cases, the two amino-terminal amino acids of the 14 aa CLE motif are not found in the mature peptides, despite their conservation across species. There is evidence that these amino acids (and perhaps others nearer to the $\mathrm{N}$-terminus of the precursor protein) constitute a protease recognition site involved in the posttranslational processing of the precursor protein into mature CLE peptides [16,17]. Generally, the CLE gene protein-coding sequences terminate with the $\mathrm{C}$ terminal amino acid of the mature CLE peptide. However, not all CLE genes conform to this paradigm, and $\mathrm{C}$-terminal non-conserved sequences (NCS2) ranging from 3 to $450 \mathrm{nt}$ (1-150 aa) have been observed in CLE genes from various species (Figure 1). These sequences

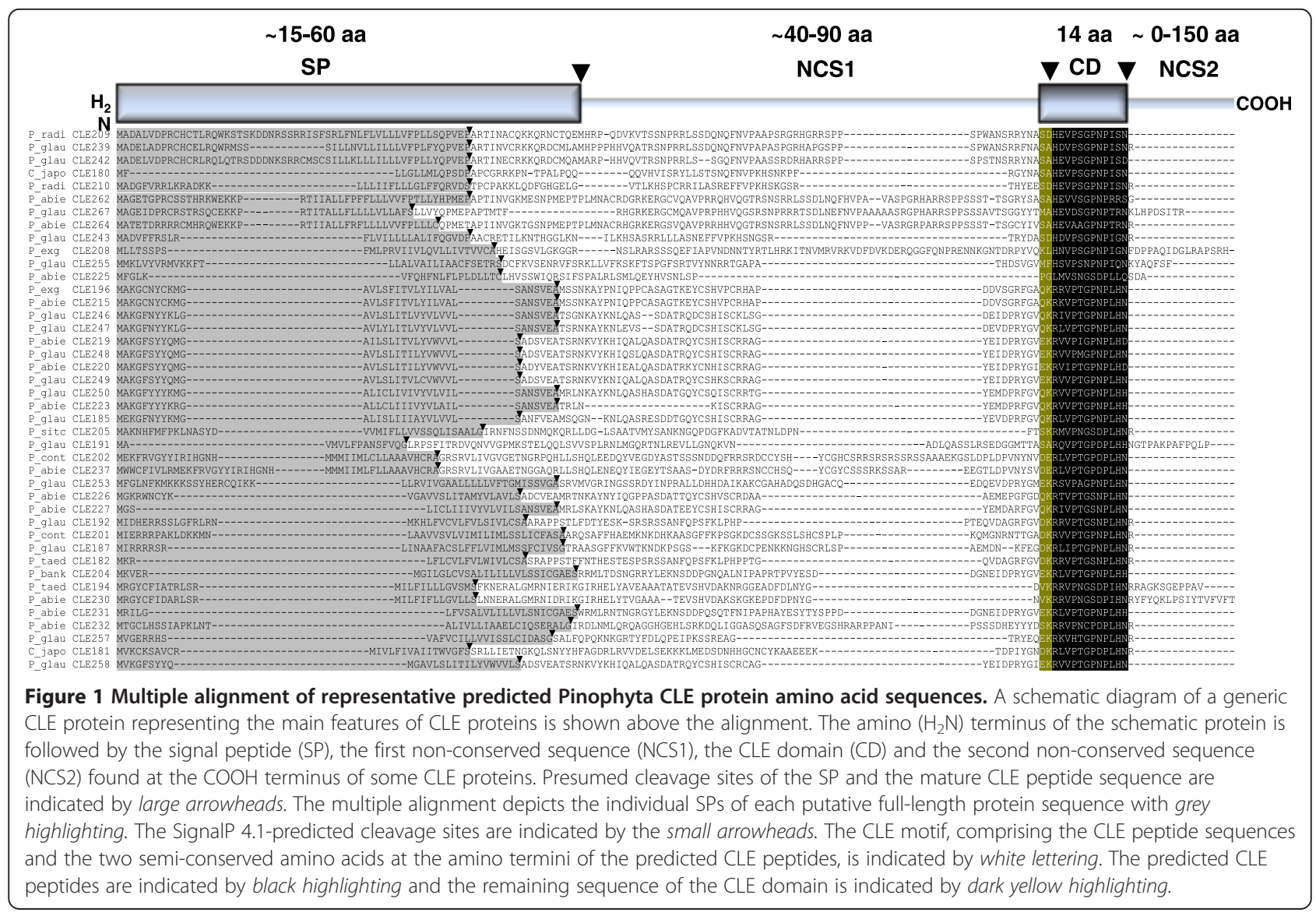


are apparently trimmed from the precursor protein by a carboxypeptidase activity [16-18].

In contrast to the CLE family, the ROOT GROWTH FACTOR/CLE-LIKE/GOLVEN (RGF/CLEL/GLV) gene family has only recently been identified and described [19-21]. Like the CLE genes, they encode short, secreted peptides that affect aspects of plant development. Structurally, the $R G F / C L E L / G L V$ genes are similar to the $C L E$ genes in that they encode precursor proteins with a signal peptide, followed by an NCS1 region with a C-terminally oriented 12-15 aa peptide that is post-translationally processed to the active form (Figure 2). Also like the CLE genes, some CLEL genes encode proteins with C-terminal NCS2 regions of varying lengths (Figure 2). The CLEL peptides, as their name suggests, have very similar sequences to the CLE peptides. A key difference between the CLE and CLEL peptides is that the CLEL peptides are variable in length at 13-16 amino acids, as compared to the 12 amino acids of the CLE peptides. Perhaps the most salient distinguishing feature between CLE and CLEL peptides is the aspartic acid-tyrosine pair at the $\mathrm{N}$-termini of all but one the RGF/CLEL/GLV active peptides. The sole exception to this rule is found in the GLV9 peptide, which contains a functionally conserved glutamic acid residue at its N-terminus in place of aspartic acid [21]. At least some of the CLEL peptides are post-translationally tyrosine sulphated, which is essential for aspects of their activity in vivo, including RAM homeostasis [19]. Interestingly, the conserved amino-terminal asp-tyr pair of the CLEL peptides is a characteristic shared with the sulphotyrosine peptide ligands PLANT PEPTIDE CONTAINING SULFATED TYROSINE 1 (PSY1) and PHYTOSULFOKINE (PSK) $[22,23]$. However, PSK and PSY1 are not otherwise similar to the CLEL peptides.

Meng et al. [20] pointed out that the RGF/CLEL/GLV peptides possess sequences that are similar to the CLE peptides. In fact, this group noted that the CLE18 gene also possessed a CLEL motif near its C-terminus in addition to its CLE18 motif, which is located in the middle of the protein. They went on to demonstrate that this CLEL motif conferred long roots to Arabidopsis plants when exogenously applied to roots in the form of a synthetic peptide. For this reason and the fact that not all of the so-called $R G F$ genes had expression patterns

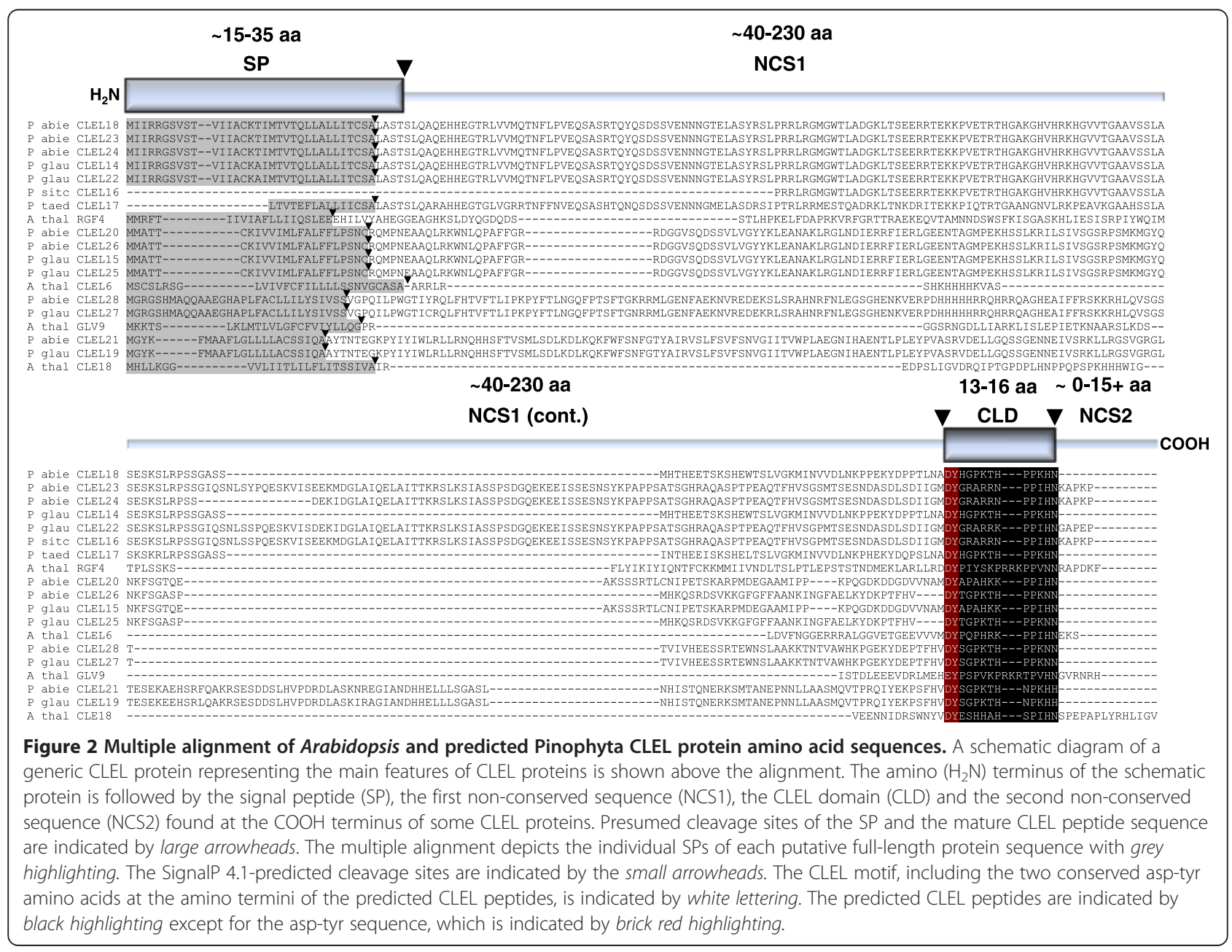


restricted to roots, they named the gene family $C L E$ LIKE (CLEL). We use this nomenclature throughout the remainder of this paper.

Based on the combined analyses of Matsuzaki et al. [19], Meng et al. [20] and Whitford et al. [21], there are at least twelve CLEL genes in the Arabidopsis genome, including CLE18, which contains both CLE and CLEL domains [20]. Whitford et al. [21] also identified 13 CLEL (GLV) genes in rice (Oryza sativa) and eleven CLEL genes in quaking aspen (Populus tremuloides). As more recently identified genes/peptides, less is understood about the CLEL family in terms of their posttranslational processing and mode(s) of action. Matsuzaki et al. [19] demonstrated that a tyrosine-sulphated form of CLEL8 (RGF1) restored RAM maintenance of a tyrosine sulphotransferase mutant in conjunction with PSK and PSY1. Root waving has been reported to result from the application of the CLE18 CLEL peptide [20] and agravitropism has been reported in clel (glv) mutants [21].

Although the vast majority of extant land plant species are angiosperms, the gymnosperms, primarily the conifers, constitute approximately one-third of earth's forest biomes [24], covering approximately $15 \%$ of global land area, primarily in the boreal forest [24]. A substantial fraction of the world's wood and wood products are derived from conifer species. Therefore, understanding the molecular basis for conifer growth and development, particularly wood formation, is critical for improvement of commercial forest productivity, necessary to meet increasing global demands for wood and wood products without increasing the rate of global deforestation [24].

Despite the economic importance of conifers, relatively little is known about growth regulation in these species. For example, no peptide ligand has been described in any gymnosperm species to date. As the CLE and CLEL peptide ligands are broadly conserved families of regulatory molecules of fundamental importance to the maintenance of meristematic tissues as well as other developmental processes, we sought to identify expressed gymnosperm homologues of these genes as a first step toward understanding the roles of peptide ligands and meristem regulation in this major phylogenetic clade.

\section{Results}

Identification of conifer CLE and CLEL genes from public EST and genome sequence data

TBLASTN searches for CLE and CLEL genes in public gymnosperm EST databases initially yielded 81 candidate CLE gene ESTs only in eight different Pinophyta species. Contig analysis yielded 31 unique contigs. Manual validation of the putative $C L E$ gene sequences resulted in the elimination of one contig from Chamaecyparis obtusa, due to weak sequence conservation, a truncated open reading frame for the presumed CLE gene and a clear open reading frame on the opposite strand. Thus, a total of 79 Pinophyta EST sequences in 30 contigs from seven different species were identified as predicted CLE genes (Additional file 1: Figure S1).

We also conducted a TBLASTN search in the NCBI/ EMBL/DDBJ gymnosperm EST databases for CLEL family members using the $A$. thaliana CLEL motif sequences. This search yielded nine ESTs, again only from conifer EST databases, from five different species. Six unique contigs were constructed from these ESTs. After manual validation and a second query with the identified conifer $C L E L$ genes, 10 ESTs in five contigs were identified as predicted CLEL genes (Additional file 2: Figure S2).

The CLE peptide motif sequences from the 30 predicted CLE genes identified in the EST searches were used to query the recently published genome sequences of two spruce species, Picea abies and P. glauca $[25,26]$ for the genomic copies of the $P$. glauca EST sequences, as well as to identify other members of the CLE gene family not previously detected in EST sequencing projects. This search resulted in the identification of 93 apparent $C L E$ genes (including presumed orthologous and paralogous genes) containing 36 different CLE sequences among the eight conifer species (Additional file 3: Table S1). Only three of the predicted CLE genes had introns (Additional file 3: Table S1). Subsequent queries of the spruce genomes with Arabidopsis CLE motifs did not identify any additional $C L E$ genes.

As with the CLE genes, the five CLEL peptide motifs were used to query the $P$. abies and P. glauca genome sequences. Unlike the CLE genes, although many putative CLEL peptide domains were identified, we could not identify any CLEL sequences that were directly downstream of a putative signal peptide domain within a continuous open reading frame (data not shown). Thus, it seemed likely that there were no CLEL genes that lacked introns within the genomes of these two organisms. Therefore, the full CLEL EST contig sequences were used in TBLASTN searches of the $P$. abies and $P$. glauca genome sequences. The results of these searches revealed extensive regions of alignment in non-contiguous segments within several genomic scaffolds of both of these species. These alignments provided approximate guides to intron/exon splice junctions to enable the construction of gene models based on the genome sequence (Figure 3). From this analysis, the predicted genomic sequences and gene structures of the two full-length $P$. glauca EST contigs CLEL14 and CLEL15 were readily identified (Figure 2, Figure 3, Additional file 3: Table S2), and these sequences were used to identify their presumed P. abies orthologues, CLEL18 and CLEL20, respectively, due to the high degree of sequence conservation between these two species (Figure 2, Figure 3, Additional file 3: Table S2). 


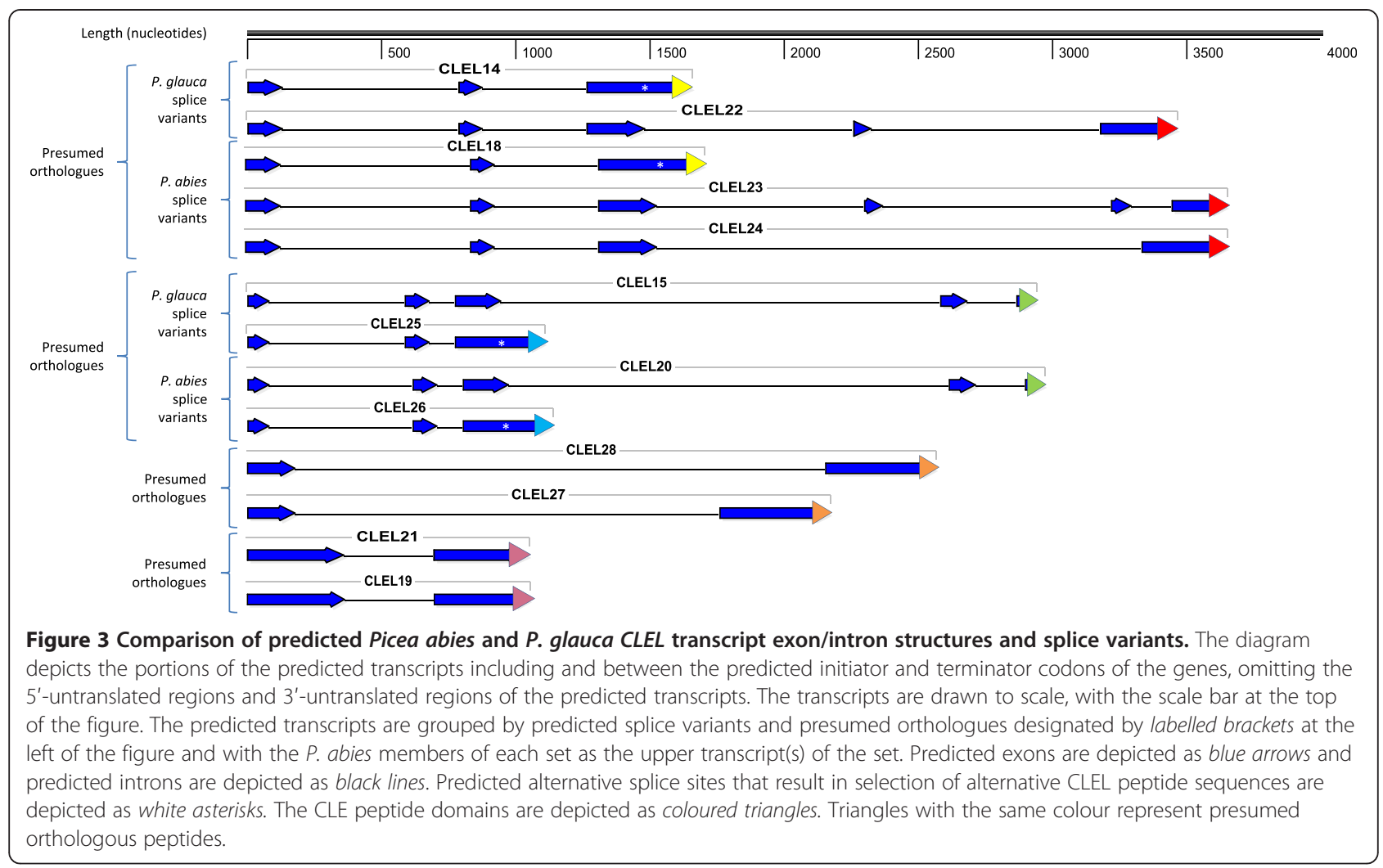

Using the $P$. engelmannii $\times$ glauca CLEL13 partial protein sequence as a query yielded the $P$. glauca gene CLEL19 and its presumed P. abies orthologue, CLEL21 (Figure 2, Figure 3, Additional file 3: Table S2). Both of these genes had only one intron (Figure 3). The identification of a putative CLEL sequence in a $P$. glauca genome sequence scaffold led us to search for a presumed $5^{\prime}$ exon containing a putative signal peptide, resulting in the identification of the predicted genes CLEL27 and CLEL28 (Figure 3, Additional file 3: Table S2). These are the only predicted $C L E L$ genes we identified that are not validated by at least some EST evidence for expression or structure. Like CLEL19 and CLEL21, these genes are predicted to have only one intron each and the predicted CLEL28 intron is the longest of any of the introns we identified in these genes.

\section{Predicted CLEL genes encode alternatively spliced transcripts with different CLEL peptide domains}

Interestingly, the TBLASTN search using the P. sitchensis CLEL16 partial protein sequence (Additional file 3: Table S2), although not full-length, revealed that this gene also aligned with the same genomic scaffold as CLEL14, but the alignment included putative protein coding segments not found in CLEL14 mapping to a long segment in NCS1 that is not shared by CLEL14 and CLEL17 (Figure 2). This prompted us to investigate possible alternative splicing in this gene, using the CLEL16 alignment as a guide. This resulted in the identification of an excellent alternative splice donor sequence (exon... $\mathrm{AG}^{\wedge} \mathrm{GTA}$...intron) in the middle of the terminal coding exon of CLEL14 (Figure 3, depicted by the white asterisk in the CLE14 schematic) and from this we identified the alternative transcript encoding the putative $P$. glauca protein CLEL22 (Figure 3, Additional file 3: Table S2), which is $98 \%$ identical to the $P$. sitchensis partial predicted protein sequence (data not shown) and encodes a CLEL peptide sequence from a different exon than that encoding the CLEL14 peptide (Figure 2, Figure 3, Additional file 3: Table S2). Examination of the presumed CLEL14 orthologue CLEL18 in P. abies for a similar splice variant yielded two genes, CLEL23 and CLEL24, which encode nearly identical protein sequences encoded by two different sets of exons due to apparent exon duplication within the locus (data not shown), with the protein sequences differing only by a 16 aa indel toward their C-termini (Figure 2, Figure 3, Additional file 3: Table S2). This alternative splicing structure encoding nearly identical proteins was not found in CLEL22 in P. glauca.

The discovery of alternative splicing in the CLEL14/ CLEL22 and CLEL18/CLEL23/CLEL24 genes led us to search for splice variants in CLEL15 and CLEL2O in P. glauca and $P$. abies respectively, as multiple CLEL domains were also identified in these scaffolds. These searches 
revealed the alternatively spliced CLEL25 and CLEL26 in the P. glauca and P. abies genomes, respectively (Figure 2, Figure 3). All the predicted alternatively spliced CLEL gene pairs (with CLEL23 and 24 considered as one half of a "pair" with CLEL18) encode transcripts that have distinct CLEL peptide sequences.

\section{Meta-analysis of conifer CLE and CLEL gene expression}

Meta-analysis of the public EST sequence data showed that most of the CLE genes were identified in bark (phloem; CLE180, 183, 190, 191, 196, 197, 198, 199, 201, 202, 203, 208), xylem (CLE186, 187, 192, 193, 200, 201, 204) root (CLE182, 184, 186, 188, 189, 194) or mixed tissue $(C L E 186,190,191,193)$ libraries (Additional file 3: Table S1). The genes that were not observed in bark, xylem or root libraries were mostly cloned from shoot/ foliage (CLE185, 186, 192, 195, 200, 205, 206, 207) libraries (Additional file 3: Table S1), with the exception of CLE180, which was also identified in a male strobilus library in addition to bark (Additional file 3: Table S1). CLE182 was the only conifer CLE gene identified from a developing embryo library and this gene was also found in both untreated and paraquat-treated root tissues of germinated plants (Additional file 3: Table S1). There was almost no overlap in the CLE genes identified between xylem and phloem tissues. The sole exception to this observation was CLE201, which was found in Pinus contorta xylem and bark libraries from wounded trees (Additional file 3: Table S1).

In contrast to the $C L E$ genes, no $C L E L$ gene was identified from xylem in our EST sequence meta-analysis. CLEL genes were primarily identified in root $(C L E L 14,17)$ and shoot $(C L E L 15,16)$ libraries, with only CLEL13 identified in a bark library (Additional file 3: Table S2). Among the CLEL genes, only CLEL14 and CLEL15 were identified in more than one library, although these were not from different tissue types (Additional file 3: Table S2).

Contig analysis of the CLE and CLEL ESTs showed very good agreement among individual reads, even among sequencing projects of different laboratory groups, which presumably used different genotypes. As expected, most of the sequence differences between contiguous transcripts were found in the predicted 5' - and 3' -UTR regions of these contigs. Only one indel that could not be attributed to a potential sequencing artefact was observed, a 20 bp insertion in the predicted $5^{\prime}$-UTR of one CLE182 transcript, which appears to be a direct repeat of the immediately following 20 bp segment (Additional file 1 : Figure S1C). Nucleotide sequence differences resulting in differences in amino acid sequence were found in CLE195, 198, 199 and 200 (Additional file 1: Figure S1P, $\mathrm{S}, \mathrm{T}, \mathrm{U}$, respectively). Predicted silent mutations were also observed in CLE195 and CLE200 (Additional file 1: Figure S1P, U). Among the CLEL ESTs, only CLEL15 showed differences, with seven amino acid differences between presumed alleles, as well as two apparent silent differences in sequence (Additional file 2: Figure S2C). There was an apparent frameshift between two CLEL17 sequences (Additional file 2: Figure S2E), but this appears likely due to an error in one of the sequences. The longer open reading frame was chosen to represent the CLEL17 protein (Additional file 2: Figure S2E, Figure 2), as this sequence was predicted to encode a signal peptide (Figure 2, Additional file 3: Table S2). This open reading frame was confirmed by the genomic sequences of putative orthologues of this gene from P. glauca and P. abies (Figure 2, Additional file 3: Table S2).

\section{Bioinformatic and phylogenetic analysis of the conifer CLE and CLEL gene contigs}

Predicted amino acid sequences of the CLE and CLEL EST consensus contigs were further analysed to determine the presence of putative signal peptides in their sequences. SignalP 4.1 [27] analysis of all CLE and CLEL amino acid sequences shows that all the predicted fulllength proteins possess predicted signal peptides, as expected of functional CLE and CLEL proteins (Figures 1 and 2, Additional file 3: Tables S1, S2).

Multiple alignment of the predicted conifer CLE and CLEL amino acid sequences revealed that several CLE genes apparently have multiple highly conserved copies in the genomic sequences, with several scaffolds harbouring identical, or nearly identical sequences (Additional file 3: Table S1). Intriguingly, the genes encoding the identical CLE232 and CLE233 proteins are found on the same scaffold (Additional file 3: Table S1), suggesting that many of these duplicated CLE and CLEL scaffolds could indeed be duplicate genes within these large genomes.

Strong sequence conservation among presumed orthologous genes across species (and genera) was also observed. For example, among the predicted proteins CLE186 (Picea glauca), CLE206 (Picea sitchensis) and CLE201 (Pinus contorta) (Figure 1), CLE186 and CLE206 show 100\% sequence conservation between these two spruce species, and these are $84.4 \%$ identical to the Pinus protein sequence.

We examined the phylogenetic relationships to Arabidopsis among the conifer CLE and CLEL precursor protein sequences as a first attempt to assess potential protein role (s) and/or function(s). A 1000-iteration Neighbour-Joining analysis grouped the conifer protein sequences with varying degrees of phylogenetic distance from the Arabidopsis CLE and CLEL clades (Figure 4). In particular, a large clade of 30 protein sequences was grouped with Arabidopsis CLE41 and CLE42 proteins and 39 other conifer proteins were grouped with Arabidopsis CLE20 (Figures 4A and 5). Among the CLEL proteins, the closest Arabidopsis Pinophyta evolutionary relationship was seen with $P$. glauca CLEL16 and Arabidopsis RGF4 (Figure 4B). CLEL17 


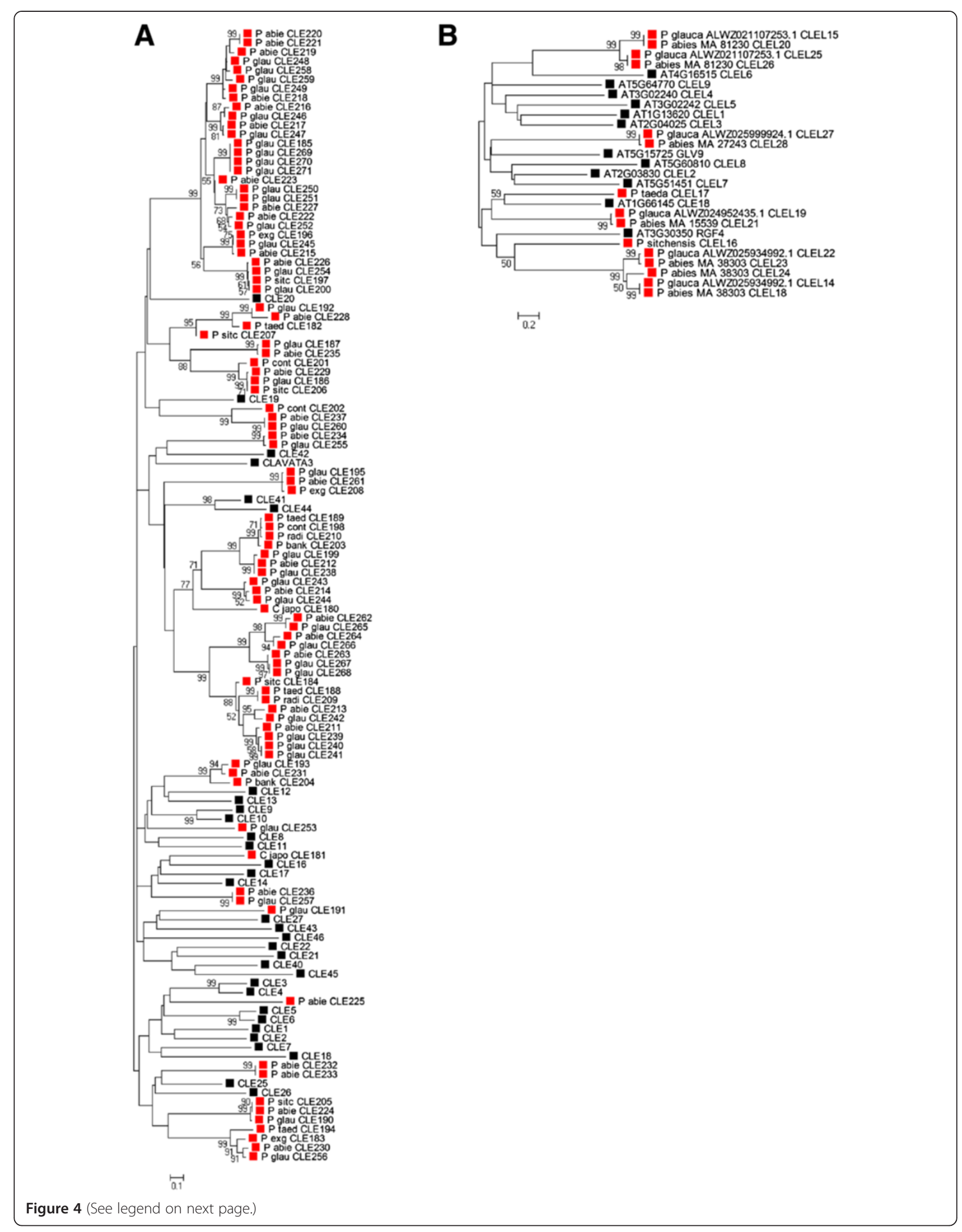


(See figure on previous page.)

Figure 4 Phylogenetic analysis of Arabidopsis and Pinophyta CLE and CLEL proteins. A 1000-iteration Neighbour-Joining analysis using the Poisson correction method with alignment gaps and missing data eliminated only in pairwise sequence comparisons was used to create bootstrap consensus trees representing the putative phylogenetic relationships among the CLE and CLEL proteins between Arabidopsis thaliana and the Pinophyta species. The trees are drawn to scale, with branch lengths in the units of the number of amino acid substitutions per site. Arabidopsis proteins are represented by black squares and Pinophyta proteins are represented by red squares. A. CLE proteins; 194 positions in the final dataset. B. CLEL proteins; 277 positions in the final dataset.

grouped with CLE18, but this relationship may be spurious, as CLEL17 is only a partial protein sequence.

To assess potential functionality of and/or roles in plant growth and development by the conifer CLE proteins, we directly compared the CLE peptide sequences to the 32 Arabidopsis CLE peptide sequences, sorted by the Arabidopsis gene overexpression phenotypes as described by Strabala et al. [4]. We grouped the conifer peptide sequences with their most closely related protein (s) as inferred from the Neighbour-Joining analysis in Figure 4A. This comparison shows that the conifer CLE peptides are in general quite closely related to their predicted Arabidopsis counterparts. Moreover, there are many examples of perfect sequence conservation of CLE peptide sequences amongst the conifer species, even across genera (Figure 5) such that the conifer CLE gene contigs can be further grouped to 36 unique predicted CLE peptide sequences (Figure 5). Interestingly, with one exception, none of the known conifer CLE peptides is perfectly conserved with an Arabidopsis peptide (Figure 5). The sole exception is the finding that ESTs encoding perfectly conserved CLE41/44-TDIF peptide sequences were found in every conifer species examined (Figure 5).

\section{Synthetic CLE peptides exert developmental effects on pine seedlings}

To begin to assess whether the close sequence conservation of the predicted CLE peptides between Arabidopsis and the Pinophyta conferred similar phenotypic effects on pine seedlings to those observed in Arabidopsis, we applied two synthetic CLE peptides, CLE13 and CLE41/ 44-TDIF to in vitro-germinated Pinus radiata zygotic embryos. These two peptides were chosen since they were either identical (CLE41/44), or differing by only one amino acid (CLE13) from predicted conifer CLE peptides (Figure 5). Additionally, these peptides belong to important CLE subfamilies that exert opposite effects on root growth, yet have been demonstrated to exert synergistic effects on the development of vascular tissue in Arabidopsis [28]. As in Arabidopsis seedlings, the CLE13 peptide inhibited root elongation at concentrations as low as $10 \mu \mathrm{M}$ (Figure 6B,E,F). CLE41/44-TDIF also inhibited root elongation in germinated pine zygotic embryos, and its effect was indistinguishable from CLE13 at $100 \mu \mathrm{M}$ concentration (Figure 6C,E,G). Combining the CLE13 and CLE41 peptides resulted in essentially the same effect as application of CLE13 alone, although some root elongation was observed in the $100 \mu \mathrm{M}$ dual application (Figure 6D,E,H). No reproducible effect on vascular tissue either in the root or the shoot was observed in these plants (data not shown).

\section{Molecular cloning and sequence analysis of Pinus radiata orthologues of CLE188 and CLE189}

We utilised the high degree of sequence conservation amongst pine species to design PCR primers based on the P. taeda CLE41/44-TDIF gene (CLE188 and CLE189) sequences for amplification and molecular cloning of presumed orthologous coding sequences from Pinus radiata genomic DNA. As expected, these primers readily amplified the putative CLE188 and CLE189 orthologues from Pinus radiata (which we named CLE209 and CLE210), which were $100 \%$ and $99.3 \%$ identical to the $P$. taeda sequences at the nucleotide level, respectively (data not shown), and 100\% (CLE209) and 98.96\% identical (CLE210) at the amino acid sequence level (Figure 1). This analysis revealed that, as expected, CLE209 and CLE210 contain no introns, at least not in their proteincoding segments (data not shown).

\section{Expression of the native CLE209/210 genes in planta and in cultured cells}

Due to the perfect sequence conservation between the CLE41/44 and CLE209/210 peptides, we sought to verify experimentally whether the phloem-specific expression localisation of the CLE41/44 genes [9] was also conserved in $P$. radiata. To test this hypothesis, we isolated total RNA from developing xylem, developing phloem and whole roots and performed qPCR experiments with primers specific for CLE209 and CLE210. As expected, expression of CLE209/210 in stems was specific to developing phloem, with very low, if any, expression in xylem cells (Figure 7A). Similar to the relative expression of CLE41 to CLE44 in Arabidopsis inflorescence stems [4], expression of CLE210 was approximately twice that of CLE209 in both phloem and root (Figure 7A). In the pine tracheary element (TE) system [29], CLE210 was at its highest abundance ( 16-fold over basal expression level) in the early part (day 2 ) of the differentiation process, and its expression levels gradually declined to about 8 -fold over basal expression levels as the number of differentiated TEs increased (Figure 7B). In contrast, CLE209 was 


\begin{tabular}{|c|c|c|c|c|}
\hline . & 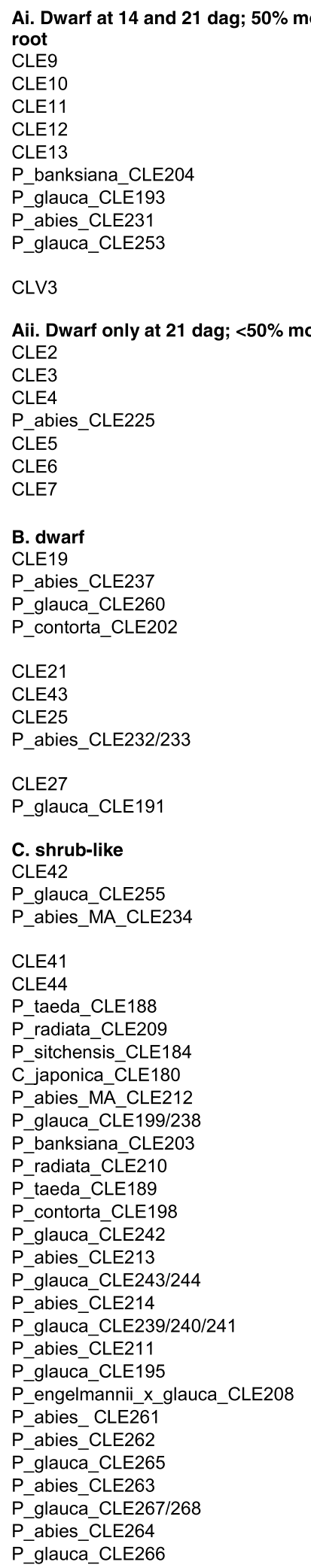 & $\begin{array}{l}\text { RVIPTGPNPLHN } \\
\text { RLVPTGPDPLHN } \\
\text { RLVPTGPDPLHN } \\
\text { RLVPTGPDPLHN } \\
\text { RSIPTGPNPLHN } \\
\text { RRIPSSPDRLHN } \\
\text { RKVPNGPDPIHN } \\
\text { RRVPNCPDPLHN } \\
\text { RIVPSCPDPLHN } \\
\text { RQVPTGPDPLHH } \\
\text { HGVSSGNPISN } \\
\text { HSVPSNPNPIQN } \\
\text { HSVPSNPNPIQN } \\
\text { HEVPSGPNPISN } \\
\text { HEVPSGPNPISN } \\
\text { HEVPSGPNPISN } \\
\text { HEVPSGPNPISN } \\
\text { HEVPSGPNPISN } \\
\text { HEVPSGPNPISN } \\
\text { HEVPSGPNPISN } \\
\text { HEVPSGPNPISN } \\
\text { HEVPSGPNPISN } \\
\text { HEVPSGPNPISN } \\
\text { HEVPSGPNPISN } \\
\text { HEVPSGPNPISN } \\
\text { HEVPSGPNPISD } \\
\text { HEVPSGPNPISD } \\
\text { HDVPSGPNPIGN } \\
\text { HDVPSGPNPIGN } \\
\text { HDVPSGPNPISN } \\
\text { HDVPSGPNPISN } \\
\text { HNVPSGPNPIGN } \\
\text { HNVPSGPNPIGN } \\
\text { HNVPSGPNPIGN } \\
\text { HEVVSGPNPRRS } \\
\text { HEVVSGPNPRRN } \\
\text { HEVDSGPNPTRN } \\
\text { HEVDSGPNPTRN } \\
\text { HEVAAGPNPTRN } \\
\text { HEVAAAPNPTRN }\end{array}$ & $\begin{array}{l}\text { D. Increased growth } \\
\text { CLE18 } \\
\text { CLE26 } \\
\text { P_glauca_CLE190 } \\
\text { P_sitchensis_CLE205 } \\
\text { P_abies_CLE224 } \\
\text { P_taeda_CLE194 } \\
\text { P_engelmannii_X_glauca_CLE183 } \\
\text { P_abies_CLE230 } \\
\text { P_glauca_CLE256 } \\
\text { No data } \\
\text { CLE1 } \\
\text { CLE8 } \\
\text { CLE14 } \\
\text { CLE16 } \\
\text { C_japonica_CLE181 } \\
\text { CLE17 } \\
\text { P_abies_CCE236 } \\
\text { P_glauca_CLE257 } \\
\text { CLE22 } \\
\text { P_abies_CLE228 } \\
\text { P_glauca_CLE192 } \\
\text { P_taeda_CLE182 } \\
\text { P_sitchensis_CLE207 } \\
\text { P_glauca_CLE187 } \\
\text { P_abies_CLE235 } \\
\text { P_contorta_CLE201 } \\
\text { P_abies_CLE229 } \\
\text { P_sitchensis_CLE206 } \\
\text { P_glauca_CLE186 } \\
\text { CLE20 } \\
\text { P_abies_CLE219 } \\
\text { P_abies_CLE220/221 } \\
\text { P_glauca_CLE248 } \\
\text { P_glauca_CLE249/258 } \\
\text { P_abies_CLE218 } \\
\text { P_abies_CLE223 } \\
\text { P_glauca_CLE250/251 } \\
\text { P_glauca_CLE259 } \\
\text { P_glauca_CLE246/252 } \\
\text { P_abies_CLE216/222 } \\
\text { P_glauca_CLE185/247/269/270/271 } \\
\text { P_abies_CLE217 } \\
\text { P_abies_CLE2277 } \\
\text { P_engelmannii_X_glauca_CLE196 } \\
\text { P_glauca_CLE245 } \\
\text { P_abies_CLE215 } \\
\text { P_abies_CLE226 } \\
\text { P_glauca_CLE200/254 } \\
\text { P_sitchensis_CLE197 } \\
\text { CLE40 } \\
\text { CLE45 } \\
\text { CLE46 }\end{array}$ & $\begin{array}{l}\text { RVVHTGPNPLHN } \\
\text { RKVHTGPNPLHN } \\
\text { RKVHTGPNPLHN } \\
\text { RRVFTGPNPLHN } \\
\text { RRVTTGSNXXVP } \\
\text { RRVPTGSNPLHN } \\
\text { RRVPTGSNPLHN } \\
\text { RRVPTGSNPLHN } \\
\text { RLIPTGPNPLHN } \\
\text { RLIPTGPNPLHN } \\
\text { RVVPTGPNPLHN } \\
\text { RVVPTGPNPLHN } \\
\text { RVVPTGPNPLHN } \\
\text { RVVPTGPNPLHN } \\
\text { RKVKTGSNPLHN } \\
\text { RVVPIGPNPLHD } \\
\text { RVIPTGPNPLHD } \\
\text { RVVPMGPNPLHN } \\
\text { RVVPTGPNPLHN } \\
\text { RVVPTGPNPLHN } \\
\text { RVVPTGPNPLHH } \\
\text { RVVPTGPNPLHH } \\
\text { RVVPTGPNPLDN } \\
\text { RIVPTGPNPLHN } \\
\text { RIVPTGPNPLHN } \\
\text { RLVPTGPNPLHN } \\
\text { RLVPTGPNPLHN } \\
\text { RIVPTGSNPLHN } \\
\text { RRVPTGPNPLHN } \\
\text { RRVPTGPNPLHN } \\
\text { RKVPTGPNPLHN } \\
\text { RTVPTGSNPLHN } \\
\text { RTVPTGSNPLHN } \\
\text { RTVPTGSNPLHN }\end{array}$ \\
\hline & legend on next page.) & & & \\
\hline
\end{tabular}


(See figure on previous page.)

Figure 5 Multiple alignment of predicted Pinophyta CLE dodecapeptide amino acid sequences. Sequences are arranged by the phenotypic classifications assigned to Arabidopsis CLE proteins in [4], with conifer sequences grouped with their closest Arabidopsis homologue, as depicted in Figure 4A. Closest matching Arabidopsis-Pinophyta homologues are indicated by boxes and light grey highlighting over the protein names. The perfectly matching predicted CLE peptides between Arabidopsis and the Pinophyta are indicated by dark grey highlighting over the Pinophyta sequences. Mismatches in the Pinophyta sequences from their closest Arabidopsis homologue are indicated by black highlighting and inverse lettering. Perfectly matching CLE peptide sequences amongst the Pinophyta species are indicated by highlighting of various colours.

only induced about 5 -fold over a much lower basal expression level relative to CLE210 such that CLE210 mRNA was $\sim 37$-fold more abundant than CLE209 at day 2 but only $\sim 6$-fold more abundant at day 10. In contrast to CLE210, the expression level of CLE209 peaked only at day 6 and apparently remained steady thereafter (Figure 7B).

\section{Discussion}

The CLE genes and peptides in plants are ancient and with a $C L E$ gene found in the genome of the bryophyte moss Physcomitrella patens, the CLE genes are distributed throughout the plant kingdom and date back more than 450 million years in plant evolutionary history [30]. This sequence conservation is likely consistent with the multiple fundamental roles that CLE peptides play in plant development. Despite such sequence conservation, $C L E$ genes had not been described to date in any conifer species. This is also the case for the CLEL genes, although this appears to be a much smaller gene family and these genes were much more recently identified and described [19-21]. Our meta-analysis of publicly available gymnosperm EST and genome sequence data revealed many $C L E$ and $C L E L$ genes in a variety of conifer species. With the exception of the presumed CLE41/44-TDIF orthologues, no predicted conifer CLE or CLEL peptide exhibited complete sequence conservation with any Arabidopsis CLE peptide (Figure 5). However, many predicted conifer CLE peptides are closely conserved with Arabidopsis CLE peptides (Figures 4 and 5) and this may suggest potential roles in conifer tree development.

Unlike most other species, analysis of the P. glauca and $P$. abies genome sequences revealed a large number of apparent paralogous genes, presumably arising from gene duplication events, encoding essentially perfectly conserved CLE proteins. Given the draft status of these genome sequences, it is unclear whether these genes are true paralogues, or simply genome assembly artefacts. However, one P. abies scaffold encoding the identical proteins CLE232 and CLE233, suggests that at least some of
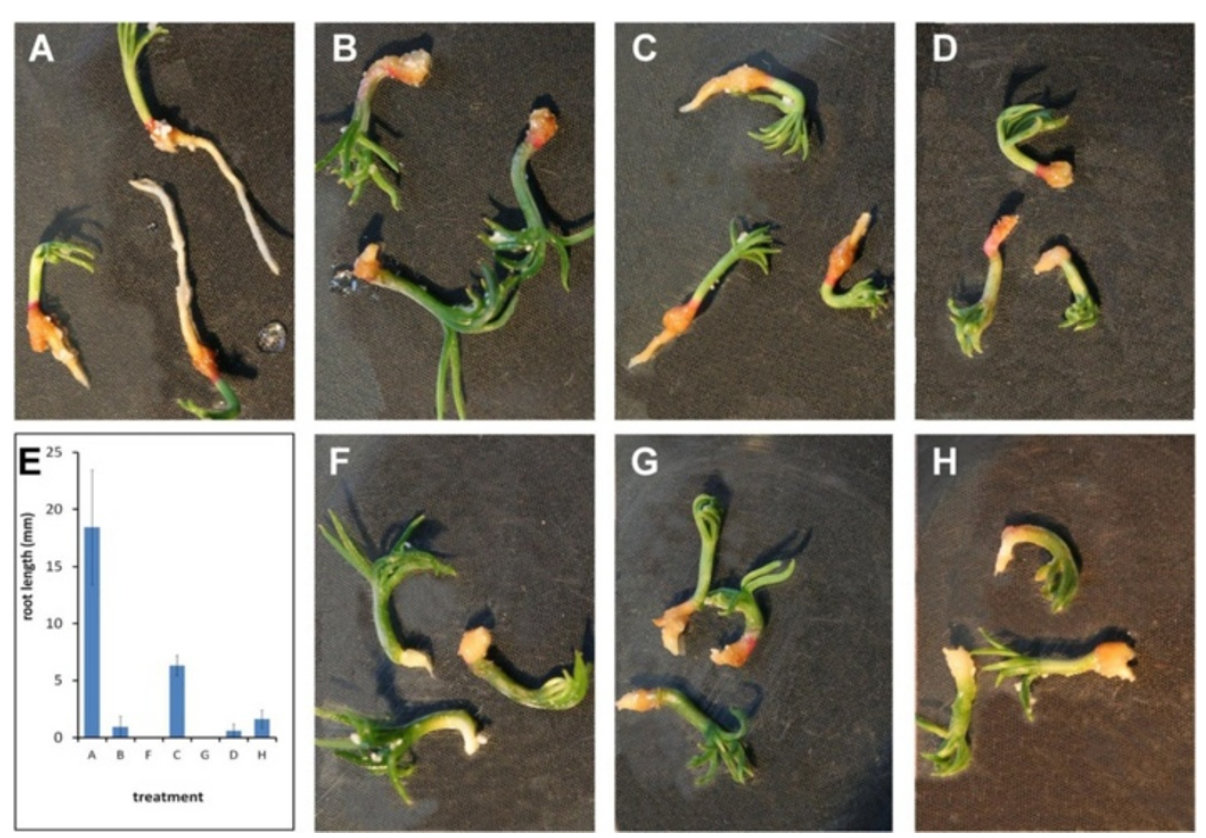

Figure 6 Synthetic CLE peptide treatments of Pinus radiata seedlings. Seedlings were either mock-inoculated (water, no peptide) (A), CLE13

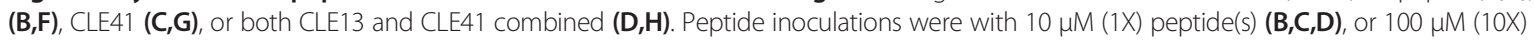
$(\mathbf{F}, \mathbf{G}, \mathbf{H})$ peptide(s). E. Plot of average root lengths observed in $\mathbf{A}-\mathbf{D}, \mathbf{F}-\mathbf{H}$, with corresponding lettering. Error bars represent the standard deviations. 

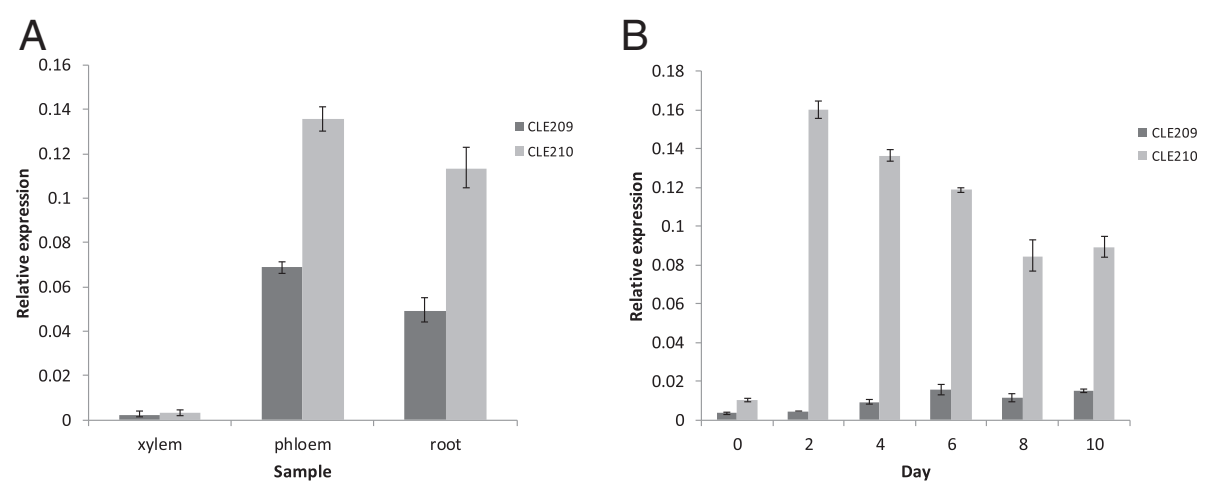

Figure 7 Expression of CLE209 and CLE210 in planta in xylem, phloem, root and differentiating pine tracheary element cultured cells. A. and B. Quantitative PCR analysis of CLE209 (dark grey bars) and CLE210 (light grey bars). A. Expression levels of CLE209 and CLE210 in xylem, phloem and root cells. B. Timecourse of expression levels of CLE209 and CLE210 in the in vitro-cultured P.radiata tracheary element differentiation system. Error bars represent standard deviations among three biological replicates. Student's $t$-test analysis of the data revealed that all expression differences were significant to a 95\% confidence interval except for the CLE209/CLE210 expression (xylem samples), for Day 4/Day 8 and Day 6/ Day 10 (CLE209 expression in the tracheary element differentiation experiments) and for Day 8/Day 10 (CLE210 expression in the tracheary element differentiation experiments).

these identical or nearly identical genes may in fact also be paralogous. Closure of scaffold gaps will be required to verify these genes.

When intraspecies and interspecies conservation of predicted CLE peptides is taken into account, 36 unique CLE dodecamer sequences are observed (Figure 5). These 36 unique sequences are comparable with the $32 C L E$ genes and 30 unique CLE dodecamer peptide sequences found in Arabidopsis. It is interesting to note that despite the high degree of sequence similarity found between the $P$. abies and $P$. glauca genomes, there is currently not complete overlap among their $C L E$ gene sequences. $C L E$ gene structure in spruce appears to parallel that of Arabidopsis, with all but two genes (CLE261 and CLE272 and its presumed P. glauca orthologue CLE191) lacking introns. Due to the draft status of the two spruce genomes, it is currently unclear whether these are the only CLE genes with introns. As with the CLEL genes, other strong matches to the CLE domains were identified in the $P$. glauca and $P$. abies genomes, but the sequences were generally near to the ends of scaffolds, so gene structure predictions could not be made. Future builds of these draft genomes with additional sequence data will likely result in the identification of additional $C L E$ and $C L E L$ genes and reveal potential orthologous genes that cannot currently be unambiguously identified.

As in Arabidopsis, it appears that the CLEL gene family comprises fewer genes than the CLE gene family. Like most Arabidopsis CLEL genes, all the predicted Pinophyta CLEL genes contain introns (Figure 3). Although alternative splicing of Arabidopsis CLEL genes has been observed, these splice events do not affect the sequence of the active peptides encoded by these genes (data not shown). Unlike the known CLEL genes, it appears that at least some of the CLEL genes in the Pinophyta are alternatively spliced to transcripts that encode proteins with different putative CLEL peptide active sequences from exons separated from each other by $\sim 1$ kilobase pair (Figure 3, Additional file 4: Figure S3, Additional file 3: Table S2). While alternative splicing events leading to slightly different isoforms of peptide ligands such as ghrelin [31] or systemin [32] have been reported, to our knowledge, this splicing of distinct, widely separated alternative exons is a unique phenomenon with regard to peptide ligands. This phenomenon in turn suggests the potential for novel mechanisms of the regulation of CLEL expression in the Pinophyta that are not known to exist in other plant species. One such mechanism might be that the alternative $C L E L$ transcripts are mutually exclusively produced in different tissue and/or cell types. Another mechanism might be the dynamic alterations of the ratio of the alternative transcripts within a cell, tissue or organ to "fine tune" a physiological or developmental process. It is conceivable that both such mechanisms could be occurring simultaneously. Regardless, these alternatively spliced CLEL forms suggest a previously unsuspected degree of dynamism in conifer signal transduction pathways.

Despite the ancient date of divergence of angiosperms from gymnosperms, estimated at 270-300 million years ago [33], conifers and dicotyledonous angiosperms still share certain characteristics not shared between the more recently diverged dicotyledon and monocotyledon angiosperm lineages. A particularly salient characteristic is the shared capacity for secondary growth between conifers and dicotyledons, which is the basis for wood formation $[34,35]$. Monocot species lack this capacity and 
achieve thickening of the stem via other mechanisms [36]. Although significant inroads have been made in understanding the regulation of secondary growth at the molecular level in dicots (particularly Arabidopsis), far less is understood about these processes in conifers. Therefore, the discovery of genes encoding perfectly conserved CLE41/44-TDIF peptide orthologues in all the Pinophyta species that are known to have CLE genes is strongly suggestive of a conserved role between conifers and dicots for these peptides in the regulation of vascular cambium homeostasis. This hypothesis is all the more compelling considering that there is essentially no other sequence conservation between these Arabidopsis and conifer gene sequences (data not shown), suggesting very strong selective pressure for the conservation of the CLE41/44-TDIF peptide sequence among species with a vascular cambium. Consistent with such a hypothesis, all the conifer CLE41/44-TDIF ESTs we identified in our EST database meta-analysis were sourced from RNA isolated from inner bark and/or phloem or root tissues (Additional file 3: Table S1). The bioinformatic metaanalysis was confirmed by our $P$. radiata qPCR results that showed phloem-specific expression in the stem, as well as expression in root (Figure 7A). This expression pattern is also consistent with that of the presumed Arabidopsis orthologues, CLE41 and CLE44 [9]. Therefore, it seems possible that the CLE41/44-TDIF genes in conifers are playing similar roles in the regulation of secondary growth to those in dicot species. This apparent conservation of a key component of the mechanism of vascular cambium homeostasis between dicot angiosperms and gymnosperms may be an indicator of the inherent capacity of these clades to make wood. Indeed, the natural variation in lignin content, neutral monosaccharide content, microfibril angle and biomechanical properties in Arabidopsis inflorescence stems showed correlations that were consistent with correlations in many of these traits in woody species [37]. Strikingly, the CLE41/44-TDIF peptide motif is only known to be conserved in only one monocot species, the date palm, Phoenix dactylifera [35], which undergoes stem thickening, although via a different mechanism that is less well understood than that of woody plants.

It is well-established that CLE41/44-TDIF is an inhibitor of in vitro TE differentiation [13] as well as xylem differentiation [9]. Therefore, the observation that the expression of the likely pine orthologues of the CLE41/44 genes are in fact apparently upregulated upon induction of pine TE differentiation (Figure 7B), seems initially counterintuitive. However, in Arabidopsis plants the CLE41/44 genes are only expressed in differentiated phloem cells [9]. Thus, in the $P$. radiata TE differentiation system [38], which presumably initially comprises dedifferentiated and/or undifferentiated cells, the expression of CLE41/44-TDIF would not be expected prior to initiation of differentiation (Figure 7). Since it is now clear that differentiated phloem cells provide developmental cues to the vascular cambium in the form of CLE41/44-TDIF to suppress xylem differentiation [9], expression of CLE41/44-TDIF is thus a specific marker for phloem cells. Therefore, the strong induction of the CLE41/44-TDIF orthologues CLE209/210 in the $P$. radiata TE system (Figure 7) indicates that the TE differentiation is accompanied by the differentiation and development of phloem or phloem-like cells and thus this in vitro system very closely parallels vascular development in planta. Hirakawa et al. [39] demonstrated a role for CLE41/44-TDIF in stimulating the proliferation of procambial cells, the cell type in which the CLE41/44-TDIF receptor, PXY, is found [9]. Thus, only upon induction of differentiation of tracheary elements is the presence of the CLE41/44-TDIF peptide required, as some non-TE cells must exist to provide signals to the cells that eventually differentiate into TEs [40] and CLE41/44-TDIF is required to maintain this undifferentiated state. Thus, the so-called tracheary element differentiation system may also be thought of as a phloem/procambium differentiation system as well.

$C L E$ gene overexpression and synthetic peptide application have been used extensively to characterise CLE functions in planta. We wished to examine the effects of CLE family members that have synergistic effects on vascular development in Arabidopsis to determine if such relationships hold in conifers. We were unable to observe any effects on vascular development in freshly germinated P.radiata seedlings because, unlike Arabidopsis, extended periods in liquid medium are not tolerated well by this species (M. West and T. Strabala, unpublished observations), leading to artefacts that obscured any effects on vascular development. However, we did find that both CLE13 and CLE41/44-TDIF peptides inhibited root development when applied to pine seedlings with some solid support, to prevent the submergence of the seedlings. CLE13, a potent inhibitor of root elongation in both Arabidopsis and rice [41] was more effective than CLE41/44TDIF in this regard. Interestingly, with application of both peptides, inhibition of root elongation appeared not to be as strong as CLE13 alone, either at 10 or $100 \mu \mathrm{M}$, or CLE41 alone at $100 \mu \mathrm{M}$ (Figure 6), so there may be some synergistic interactions between these peptides in pine as well.

It was somewhat unexpected that CLE41 peptide inhibited root development in pine at all, since experiments in Arabidopsis have shown that has no effect on root elongation either when overexpressed [4], or when exogenously applied [13,41]. However, Kinoshita et al. [41] demonstrated that CLE41/44 had a mild inhibitory effect on root elongation in rice when applied to roots at a $1 \mu \mathrm{M}$ concentration. Presumably, this inhibition would have been 
greater at a $10 \mu \mathrm{M}$ concentration (which was the lowest concentration we used on the pine seedlings), so it appears that this root response to exogenous CLE41/44 is shared between pine and rice. The basis for this shared response is not yet clear. CLE41/44 is not an endogenous peptide in rice as it is in conifers and dicots. Despite the conservation of the CLE41/44 peptide in conifers, $P$. radiata is substantially evolutionarily diverged from $A$. thaliana. Additionally, such experiments provide CLE peptides at significantly higher concentrations than is found in vivo (and likely above the dissociation constants of many non-cognate receptors). This situation likely causes CLE peptides to bind to receptors that they would not normally bind, resulting in neomorphic or antimorphic phenotypes [42]. Although it appears that CLE41/44-TDIF phloemspecific expression in Arabidopsis is conserved [9], which implies a putative PXY receptor orthologue in pine, the ectopic responses of other receptors resulting from interaction with CLE41/44-TDIF may not be the same as Arabidopsis in all cases.

\section{Conclusions}

The CLE and CLEL peptide ligand families are well known to play many important roles in angiosperm plant growth and development. Conifer and dicot angiosperm taxa share certain growth characteristics, most notably a vascular cambium, not shared by monocot angiosperms, yet they differ fundamentally in many other aspects of their growth and development. We show that CLE and CLEL genes are found in the Pinophyta with gene numbers and sequence diversity similar to angiosperms, yet their active peptide sequences are not perfectly conserved, with one exception, the conserved CLE41/44-TDIF peptide. Our experiments involving this peptide and $P$. radiata orthologues of the genes encoding are suggestive that they play orthologous roles in vascular development among conifer and dicot species. Conversely, we provide evidence that at least some $C L E L$ genes appear to be regulated in completely different ways than their angiosperm counterparts, via splicing of alternative exons that encode different CLEL peptides. The substantial sequence differences between these alternate peptides suggest that they either bind different receptors, or if they interact with the same receptor, they do so with different affinities and/or binding sites. Although alternative transcript splicing is a thoroughly studied phenomenon, to our knowledge, this is a completely novel means to regulate the expression of peptide signalling ligands. Further comparative analysis of these signalling ligand gene families in conifers and dicot angiosperms will surely lead to deeper understanding of growth and developmental processes in both of these major phylogenetic clades and our ability to manipulate these processes for more sustainable wood and wood product production.

\section{Methods}

\section{Bioinformatic analysis}

TBLASTN searches, using the NCBI-hosted BLAST search tool (http://blast.ncbi.nlm.nih.gov/Blast.cgi) were conducted. Each known Arabidopsis thaliana CLE and $C L E L$ gene was used as a query sequence against the NCBI EST DNA Spermatophyta (seed plants) database (NCBI taxid 58024), excluding the Magnoliophyta (NCBI taxid 3398) to allow searching of all gymnosperm species, were performed. Sequence hits were then further analysed using GAP4 [43] to sort the hits into contigs, combined with manual editing with particular attention to species of origin due to high levels of sequence conservation across species with several of the CLE genes. The consensus sequences from all validated contigs were used as query sequences in a second round of TBLASTN analysis of the Pinophyta database subset to identify sequences that were not initially identified in the original TBLASTN searches, both to extend the contigs and to ensure that no CLE or $C L E L$ sequences were overlooked due to truncated sequences lacking a CLE or CLEL domain. These sequences were also used to query the Picea abies and Picea glauca genome sequence V1.0 assemblies [25,26], to search for genes that might not have been detected in EST databases.

In the case of EST contigs, protein sequences were assumed to be full-length if the use of the $5^{\prime}$-most predicted in-frame Met residue of the CLE or CLEL contig predicted amino acid sequence yielded a signal peptide. If a signal peptide was not identified at this stage, the contig was assumed not to be full-length. If the contig was of a $P$. glauca sequence, then a full-length genomic sequence was sought. Putative CLE genes were selected from genomic sequences on the basis of having a hit to the CLE motif query sequence, plus an open reading frame with at least one met residue as an initiator codon and a downstream predicted signal peptide. Protein sequences were analysed for signal peptide sequences using the SignalP 4.1 server [27]. In the case of genomic sequences, the lack of a signal peptide was interpreted to mean that the initial CLE motif hit was likely to be spurious and the sequence was not examined further. Multiple sequence alignments and phylogenetic trees were generated using MEGA, version 4.0.2 (http://www. megasoftware.net/mega4/mega.html) [44].

\section{CLE peptide treatments of pine embryos}

Synthetic peptides, obtained from Auspep (Parkville, Australia), were dissolved in $50 \mathrm{mM}$ sodium phosphate buffer ( $\mathrm{pH}$ 6.0) and stored at ${ }^{-} 80^{\circ} \mathrm{C}$. Pinus radiata zygotic embryos were grown under sterile conditions for $13 \mathrm{~d}$ in 
$50 \mathrm{ml}$ Falcon tubes containing $1 \mathrm{~g}$ of perlite and $4 \mathrm{ml}$ of $\mathrm{KNV}$ medium [45]. Plants were grown $16 \mathrm{~h} / 25^{\circ} \mathrm{C}$ day (80 $\mu \mathrm{E} \mathrm{m} \mathrm{m}^{-2} \mathrm{~s}^{-1}$ light intensity) and $8 \mathrm{~h} / 18^{\circ} \mathrm{C}$ night. CLE peptide-treated embryos were grown as for the negative controls with either added CLE13 (H-Arg-Leu-Val-HypSer-Gly-Hyp-Asn-Pro-Leu-His-His-OH) or CLE41 (HHis-Glu-Val-Hyp-Ser-Gly-Hyp-Asn-Pro-Ile-Ser-Asn-OH) (Hyp = hydroxyproline) at either $10 \mu \mathrm{M}(1 \mathrm{X})$ or $100 \mu \mathrm{M}$ (10X) final concentration.

\section{Nucleic acid extractions from pine tissues}

Genomic DNA was extracted from $P$. radiata embryogenic callus tissue essentially as described [46]. Total RNA was extracted from $P$. radiata induced xylogenic callus material at $0,2,4,6,8$ and 10 days post-induction [29] or from uninduced callus material at equivalent time points using Purelink ${ }^{\ominus}$ Plant RNA reagent (Ambion, Life Technologies) as per the manufacturer's instructions.

For extraction of total RNA from $P$. radiata xylem, phloem and root, tissue samples constituting early season (spring) vascular cambium formation were collected from a two-year-old glasshouse-grown tree. Bark was peeled from most of the stem and developing xylem scrapings were taken along the length of the stem, avoiding tissue near branch whorls. Phloem tissue was carefully cut into sections from the inner surface of the bark peelings. Root samples were excised and quickly washed in phosphate buffer to rinse off potting mix. All tissue samples were snap-frozen in liquid nitrogen and stored at $-80^{\circ} \mathrm{C}$ prior to RNA extraction. Approximately $0.5 \mathrm{~g}-1.0 \mathrm{~g}$ of frozen tissue was ground to a fine powder with a mortar and pestle under liquid nitrogen and quickly transferred to a $50 \mathrm{ml}$ tube containing $10 \mathrm{ml}$ of CTAB extraction buffer $(2 \%$ CTAB, 2\% PVP-40, $2.0 \mathrm{M} \mathrm{NaCl}, 100 \mathrm{mM}$ Tris- $\mathrm{HCl}$ pH8.0, $25 \mathrm{mM}$ EDTA pH8.0) to which $2 \% \beta$-mercaptoethanol had been freshly added, preheated to $65^{\circ} \mathrm{C}$. Samples were incubated for $30 \mathrm{~min}$ at $65^{\circ} \mathrm{C}$, with occasional mixing by inversion, then extracted twice with $10 \mathrm{ml}$ of chloroform/ isoamyl alcohol $(24: 1 \mathrm{v} / \mathrm{v})$, mixed by careful inversion for at least $5 \mathrm{~min}$, then centrifuged at $9500 \times \mathrm{g}, 4^{\circ} \mathrm{C}$ for $10 \mathrm{~min}$. Aqueous supernatants were transferred to clean $15 \mathrm{ml}$ tubes and $1 / 4$ volumes of $10 \mathrm{M} \mathrm{LiCl}$ were added to each tube, mixed by careful inversion and precipitated overnight at $4^{\circ} \mathrm{C}$. Precipitates were pelleted by centrifugation at $13000 \times \mathrm{g}, 4^{\circ} \mathrm{C}$ for $30 \mathrm{~min}$. Supernatants were decanted and the RNA pellets were redissolved in $1 \mathrm{ml} \mathrm{STE}$ buffer (1 M NaCl, 10 mM Tris- $\mathrm{HCl}$ pH8.0, 1 mM EDTA pH8.0), maintaining a temperature of $0^{\circ} \mathrm{C}$ throughout. RNA was reprecipitated by addition of $2 \times$ volumes of absolute ethanol $\left(-20^{\circ} \mathrm{C}\right)$. Precipitates were pelleted by centrifugation as before, washed with $1 \times$ volume of $70 \%$ ethanol and pelleted again as before. RNA pellets were air-dried and resuspended in 200-300 $\mu \mathrm{l} 10 \mathrm{mM}$ Tris- $\mathrm{HCl}$ $\mathrm{pH} 8.0$, depending on apparent yield, and stored at $-80^{\circ} \mathrm{C}$.

\section{Quantitative RT-PCR of $P$. radiata total RNA}

Messenger RNA was isolated from total RNA using Dynabeads $^{\oplus}$ oligo $(\mathrm{dT})_{25}$ (Ambion, Life Technologies) following the manufacturer's instructions. First-strand cDNA was synthesised from the mRNA using a qScript ${ }^{\mathrm{rm}}$ Flex cDNA synthesis kit (Quanta Biosciences) and priming with the oligo-dT included. The cDNA was quantified on a fluorometer using Quant-i $\mathrm{T}^{\mathrm{TM}}$ Oligreen ssDNA reagent (Molecular Probes, Life Technologies). Realtime PCR was performed on a LightCycler 1.5 (Roche) using a LightCycler ${ }^{\odot}$ FastStart DNA Master ${ }^{\text {PLUS }}$ SYBR Green I kit as previously described [47], with the PCR reaction volume scaled down to $10 \mu \mathrm{l}$. Statistical significance of differences in expression levels between samples was determined using Student's $t$-test [48].

\section{Molecular cloning of CLE209 and CLE210}

EST sequences from Pinus taeda, GenBank/EMBL/DDBJ accession numbers CO365940 and DR744109 were used to design primer sequences for the amplification of the orthologous genes from Pinus radiata using the following primer pairs:

\section{5'-GCTCTAGAATGGCAGATGCTTTAGTGGAT-3' and \\ 5'-GCGCGGCCGCTCAATTTGATATTGGATTTGG ACCG-3' (CLE188); \\ 5'-GCTCTAGAATGGCGGATGGTTTTGTT-3' and 5'-GCGCGGCCGCTTACCTATTACTAATTGGAT TTGGAC-3' (CLE189)}

Xba I and Not I restriction enzyme recognition sequences were incorporated in the $5^{\prime}$ ends of forward and reverse primers respectively to facilitate directional cloning. Gene sequences were amplified in a total volume of $50 \mu \mathrm{L}$ using $50 \mathrm{ng}$ of genomic DNA, $2.5 \mathrm{U}$ of Roche Expand High Fidelity ${ }^{\text {PLUS }}$ DNA polymerase, $2.5 \mathrm{mM} \mathrm{MgCl}_{2}$, $300 \mu \mathrm{M}$ dNTPs and $300 \mathrm{nM}$ of each primer. PCR parameters were: initial denaturation at $94^{\circ} \mathrm{C}$ for 2 mins, followed by 30 cycles of $94^{\circ} \mathrm{C}$ for $30 \mathrm{~s}, 50^{\circ} \mathrm{C}$ for $30 \mathrm{~s}$ and $72^{\circ} \mathrm{C}$ for $1 \mathrm{~min}$, a final extension of $72^{\circ} \mathrm{C}$ for $5 \mathrm{~min}$. Completed reactions were held at $10^{\circ} \mathrm{C}$.

\section{Additional files}

Additional file 1: Figure S1. Contig analysis of putative conifer CLE gene ESTs. Putative CLE gene ESTs were identified, and contig alignments and assignments were performed as described in Methods. Putative signal peptide analysis was conducted using the SignalP 4.1 server (Technical University of Denmark), respectively. Predicted open reading frames are highlighted in turquoise, except for the putative CLE peptide sequences, which are highlighted in yellow. Putative signal peptide cleavage sites are denoted by arrowheads. Potential in-frame ribosome initiation codons consistent with a signal peptide are highlighted in teal. 
Additional file 2: Figure S2. Contig analysis of putative conifer CLEL gene ESTs. Putative CLEL gene ESTs were identified, and contig alignments and assignments were performed as described in Methods. Putative signal peptide analysis was conducted as described in Figure S1 Predicted open reading frames are highlighted in turquoise, except for the putative CLE peptide sequences, which are highlighted in yellow. Putative signal peptide cleavage sites are denoted by arrowheads. Potential in-frame ribosome initiation codons consistent with a signal peptide are highlighted in teal.

Additional file 3: Table S1. CLE genes and proteins in the Pinophyta. Excel file, "Strabala et al Tables S1 + S2"; tab labelled "Table S1 - CLE genes". Table S2. CLEL genes and proteins in the Pinophyta. Excel file, "Strabala et al Tables S1 + S2"; tab labelled "Table S2 - CLEL genes".

Additional file 4: Figure S3. Multiple alignment of predicted Pinophyta CLEL peptide amino acid sequences. Sequences are arranged as depicted in Figure $4 \mathrm{~B}$ with conifer sequences grouped with their closest Arabidopsis homologue. Closest matching Arabidopsis-Pinophyta homologues are positioned directly beneath their putative closest Arabidopsis homologue Arabidopsis gene names are signified with grey highlighting. Mismatches in the Pinophyta sequences from their closest Arabidopsis homologues are indicated by black highlighting and inverse lettering.

\section{Abbreviations}

BLAST: Basic local alignment search tool; CLE: Clavata/embryo-surrounding region (gene or protein); CLE41/44-TDIF: CLE41/44-tracheary element differentiation factor; CLEL: CLE - Like (gene or protein); EST: Expressed sequence tag; NCS: Non-conserved sequence; PSK: Phytosulphokine (gene or protein); PSY1: Plant peptide containing sulphated tyrosine 1 (gene or protein); RAM: Root apical meristem; RLK: Receptor-like kinase; SAM: Shoot apical meristem.

\section{Competing interests}

The authors declare that they have no competing interests.

\section{Authors' contributions}

TJS conceived the study, conducted the bioinformatic analysis and drafted the manuscript. LP did the RNA purifications, the GPCR analyses, part of the cloning and participated in the drafting of the manuscript. MW did the CLE peptide application experiments and participated in the drafting of the manuscript and LS did part of the cloning and participated in the drafting of the manuscript. All authors read and approved the final manuscript.

\section{Acknowledgements}

We thank Anne-Marie Smit for statistical analysis, Joseph Dubouzet for helpful discussions, and Armin Wagner and Glenn Thorlby for critical reading of the manuscript. This work was supported in part by the Foundation for Research, Science \& Technology (New Zealand), grant number C04X0703.

Received: 15 September 2013 Accepted: 10 February 2014 Published: 14 February 2014

\section{References}

1. Fletcher JC, Brand U, Running MP, Simon R, Meyerowitz EM: Signaling of cell fate decisions by CLAVATA3 in Arabidopsis shoot meristems. Science 1999, 283:1911-1914.

2. Cock JM, McCormick S: A large family of genes that share homology with CLAVATA3. Plant Physiol 2001, 126(3):939-942.

3. Oelkers K, Goffard N, Weiller GF, Gresshoff PM, Mathesius U, Frickey T: Bioinformatic analysis of the CLE signaling peptide family. BMC Plant Biol 2008, 8(1):1.

4. Strabala TJ, O'Donnell PJ, Smit A-M, Ampomah-Dwamena C, Martin EJ, Netzler N, Nieuwenhuizen N, Quinn B, Foote HCC, Hudson KR: Gain-of-function phenotypes of many CLAVATA3/ESR genes, including four new family members, correlate with tandem variations in the conserved CLAVATA3/ESR domain. Plant Physiol 2006, 140(4):1331-1344.

5. Fiume E, Fletcher JC: Regulation of Arabidopsis embryo and endosperm development by the polypeptide signaling molecule CLE8. Plant Cell 2012, 24:1000-1012.

6. Dodueva IE, Yurlova EV, Osipova MA, Lutova LA: CLE peptides are universal regulators of meristem development. Russ J Plant Physiol 2012, 59(1):14-27.
7. Rojo E, Sharma VK, Kovaleva V, Raikhel NV, Fletcher JC: CLV3 is localized to the extracellular space, where it activates the arabidopsis CLAVATA stem cell signaling pathway. Plant Cell 2002, 14:969-977.

8. Stahl Y, Wink RH, Ingram GC, Simon R: A signaling module controlling the stem cell niche in Arabidopsis root meristems. Curr Biol 2009, 19(11):909-914.

9. Etchells JP, Turner SR: The PXY-CLE41 receptor ligand pair defines a multifunctional pathway that controls the rate and orientation of vascular cell division. Development 2010, 137(5):767-774.

10. Lim CW, Lee YW, Hwang CH: Soybean nodule-enhanced CLE peptides in roots act as signals in GmNARK-mediated nodulation suppression. Plant Cell Physiol 2011, 52(9):1613-1627.

11. Mortier V, Den Herder G, Whitford R, Van de Velde W, Rombauts S, D'Haeseleer K, Holsters M, Goormachtig S: CLE peptides control Medicago truncatula nodulation locally and systemically. Plant Physiol 2010, 153(1):222-237.

12. Okamoto S, Ohnishi E, Sato S, Takahashi H, Nakazono M, Tabata S, Kawaguchi M: Nod factor/nitrate-induced CLE genes that drive HAR1mediated systemic regulation of nodulation. Plant Cell Physiol 2009, 50(1):67-77.

13. Ito Y, Nakanomyo I, Motose H, Iwamoto K, Sawa S, Dohmae N, Fukuda H: Dodeca-CLE peptides as suppressors of plant stem cell differentiation. Science 2006, 313(5788):842-845.

14. Kondo T, Sawa S, Kinoshita A, Mizuno S, Kakimoto T, Fukuda H, Sakagami Y: A plant peptide encoded by CLV3 identified by in situ MALDI-TOF MS analysis. Science 2006, 313(5788):845-848.

15. Ohyama K, Shinohara H, Ogawa-Ohnishi M, Matsubayashi Y: A glycopeptide regulating stem cell fate in Arabidopsis thaliana. Nat Chem Biol 2009, 5:578-580.

16. Djordjevic MA, Oakes M, Wong CE, Singh M, Bhalla P, Kusumawati L, Imin N: Border sequences of Medicago truncatula CLE36 are specifically cleaved by endoproteases common to the extracellular fluids of Medicago and soybean. J Exp Bot 2011, 62(13):4649-4659.

17. $\mathrm{Ni}$ J, Guo Y, Jin H, Hartsell J, Clark S: Characterization of a CLE processing activity. Plant Mol Biol 2011, 75(1):67-75.

18. Casamitjana-Martinez E, Hofhuis HF, Xu J, Liu CM, Heidstra R, Scheres B: Root-specific CLE19 overexpression and the sol1/2 suppressors implicate a CLV-like pathway in the control of Arabidopsis root meristem maintenance. Curr Biol 2003, 13(16):1435-1441.

19. Matsuzaki Y, Ogawa-Ohnishi M, Mori A, Matsubayashi Y: Secreted peptide signals required for maintenance of root stem cell niche in Arabidopsis. Science 2010, 329(5995):1065-1067.

20. Meng L, Buchanan BB, Feldman LJ, Luan S: CLE-like (CLEL) peptides control the pattern of root growth and lateral root development in Arabidopsis. Proc Natl Acad Sci 2012, 109(5):1760-1765.

21. Whitford R, Fernandez A, Tejos R, Pérez Amparo C, Kleine-Vehn J, Vanneste S, Drozdzecki A, Leitner J, Abas L, Aerts M, Hoogewijs K, Baster P, De Groodt R, Lin Y-C, Storme V, Van de Peer Y, Beeckman T, Madder A, Devreese B, Luschnig C, Friml J, Hilson P: GOLVEN secretory peptides regulate auxin carrier turnover during plant gravitropic responses. Dev Cell 2012, 22(3):678-685.

22. Amano Y, Tsubouchi H, Shinohara H, Ogawa M, Matsubayashi Y: Tyrosinesulfated glycopeptide involved in cellular proliferation and expansion in Arabidopsis. Proc Natl Acad Sci 2007, 104:18333-18338.

23. Yang H, Matsubayashi Y, Nakamura K, Sakagami Y: Diversity of Arabidopsis genes encoding precursors for phytosulfokine, a peptide growth factor. Plant Physiol 2001, 127(3):842-851.

24. FAO: Global forest land-use change from 1990 to 2005 : initial results from a global remote sensing survey. In Food and Agriculture Organization of the United Nations; 2011.

25. Nystedt B, Street NR, Wetterbom A, Zuccolo A, Lin Y-C, Scofield DG, Vezzi F, Delhomme N, Giacomello S, Alexeyenko A, Vicedomini R, Sahlin K, Sherwood E, Elfstrand M, Gramzow L, Holmberg K, Hällman J, Keech O Klasson L, Koriabine M, Kucukoglu M, Käller M, Luthman J, Lysholm F, Niittylä T, Olson Å, Rilakovic N, Ritland C, Rosselló JA, Sena J, et al: The Norway spruce genome sequence and conifer genome evolution. Nature 2013, 497:579-584.

26. Birol I, Raymond A, Jackman SD, Pleasance S, Coope R, Taylor GA, Yuen MMS, Keeling Cl, Brand D, Vandervalk BP, Kirk H, Pandoh P, Moore RA, Zhao Y, Mungall AJ, Jaquish B, Yanchuk A, Ritland C, Boyle B, Bousquet J, Ritland K, Mackay J, Bohlmann J, Jones SJ: Assembling the $20 \mathrm{~Gb}$ white spruce (Picea glauca) genome from whole-genome shotgun sequencing data. Bioinformatics 2013, 29(12):1492-1497. 
27. Petersen T, Brunak S, von Heijne G, Nielsen H: SignalP 4.0: discriminating signal peptides from transmembrane regions. Nat Meth 2011, 8(10):785-786.

28. Whitford R, Fernandez A, De Groodt R, Ortega E, Hilson P: Plant CLE peptides from two distinct functional classes synergistically induce division of vascular cells. Proc Natl Acad Sci 2008, 105:18625-18630

29. Möller R, Ball R, Henderson A, Modzel G, Find J: Effect of light and activated charcoal on tracheary element differentiation in callus cultures of Pinus Radiata D. Don. Plant Cell Tiss Organ Cult 2006, 85(2):161-171.

30. Rensing SA, Lang D, Zimmer AD, Terry A, Salamov A, Shapiro H, Nishiyama T, Perroud P-F, Lindquist EA, Kamisugi Y, Tanahashi T, Sakakibara K, Fujita T, Oishi K, Shin-I T, Kuroki Y, Toyoda A, Suzuki Y, Hashimoto S-i, Yamaguchi K, Sugano S, Kohara Y, Fujiyama A, Anterola A, Aoki S, Ashton N, Barbazuk WB, Barker E, Bennetzen $J L$, Blankenship $R$, et al: The Physcomitrella genome reveals evolutionary insights into the conquest of land by plants. Science 2008, 319(5859):64-69

31. Hosoda H, Kojima M, Matsuo H, Kangawa K: Purification and characterization of rat des-Gln14-ghrelin, a second endogenous ligand for the growth hormone secretagogue receptor. J Biol Chem 2000, 275(29):21995-22000.

32. Li L, Howe G: Alternative splicing of prosystemin pre-mRNA produces two isoforms that are active as signals in the wound response pathway. Plant Mol Biol 2001, 46(4):409-419.

33. Bowe $L M$, Coat $G$, dePamphilis CW: Phylogeny of seed plants based on all three genomic compartments: extant gymnosperms are monophyletic and Gnetales' closest relatives are conifers. Proc Natl Acad Sci USA 2000, 97(8):4092-4097.

34. Evert RF: Esau's Plant Anatomy: Meristems, Cells, and Tissues of the Plant Body: Their Structure, Function, and Development. 3rd edition. Hoboken: John Wiley \& Sons, Inc; 2006.

35. Strabala TJ, MacMillan CP: The Arabidopsis wood model - the case for the inflorescence stem. Plant Sci 2013, 210:193-205.

36. Rudall P: New records of secondary thickening in monocotyledons. IAWA J 1995, 16(3):261-268

37. MacMillan CP, O'Donnell PJ, Smit A-M, Evans R, Stachurski ZH, Torr K, West M, Baltunis J, Strabala TJ: A survey of the natural variation in biomechanical and cell wall properties in inflorescence stems reveals new insights into the utility of Arabidopsis as a wood model. Funct Plant Biol 2013, 40(7):662-676.

38. Möller R, McDonald AG, Walter C, Harris PJ: Cell differentiation, secondary cell-wall formation and transformation of callus tissue of Pinus radiata D. Don. Planta 2003, 217(5):736.

39. Hirakawa Y, Shinohara H, Kondo Y, Inoue A, Nakanomyo I, Ogawa M, Sawa S, Ohashi-Ito K, Matsubayashi Y, Fukuda H: Non-cell-autonomous control of vascular stem cell fate by a CLE peptide/receptor system. Proc Natl Acad Sci USA 2008, 105(39):15208-15213.

40. McCann MC, Stacey NJ, Dahiya P, Milioni D, Sado P-E, Roberts K: Zinnia. Everybody needs good neighbors. Plant Physiol 2001, 127(4):1380-1382.

41. Kinoshita A, Nakamura Y, Sasaki E, Kyozuka J, Fukuda H, Sawa S: Gain-offunction phenotypes of chemically synthetic CLAVATA3/ESR-related (CLE) peptides in Arabidopsis thaliana and Oryza sativa. Plant Cell Physiol 2007, 48(12):1821-1825.

42. Strabala TJ: CLE genes in plant development: gain-of-function analyses, pleiotropy, hypermorphy and neomorphy. Plant Signal Behav 2008, 3(7):457-459.

43. Staden R: The Staden sequence analysis package. Mol Biotechnol 1996, 5:233-241.

44. Tamura K, Dudley J, Nei M, Kumar S: MEGA4: molecular evolutionary genetics analysis (MEGA) software version 4.0. Mol Biol Evol 2007, 24:1596-1599.

45. Krogstrup P, Nielson EN, Møller JD, Rouland H: Somatic embryogenesis in sitka spruce (Picea sitchensis (Bong.) Carr.). Plant Cell Rep 1988, 7:594-597.
46. Doyle JJ, Doyle JL: Isolation of plant DNA from fresh tissue. Focus 1990 12:13-15.

47. Cato S, McMillan L, Donaldson L, Richardson T, Echt C, Gardner R: Wood formation from the base to the crown in Pinus radiata: gradients of tracheid wall thickness, wood density, radial growth rate and gene expression. Plant Mol Biol 2006, 60:565-581.

48. Student: The probable error of a mean. Biometrika 1908, 6:1-25.

doi:10.1186/1471-2229-14-47

Cite this article as: Strabala et al.: Bioinformatic and phylogenetic analysis of the CLAVATA3/EMBRYO-SURROUNDING REGION (CLE) and the CLE-LIKE signal peptide genes in the Pinophyta. BMC Plant Biology 2014 14:47.

\section{Submit your next manuscript to BioMed Central and take full advantage of:}

- Convenient online submission

- Thorough peer review

- No space constraints or color figure charges

- Immediate publication on acceptance

- Inclusion in PubMed, CAS, Scopus and Google Scholar

- Research which is freely available for redistribution

Submit your manuscript at www.biomedcentral.com/submit
( Biomed Central 